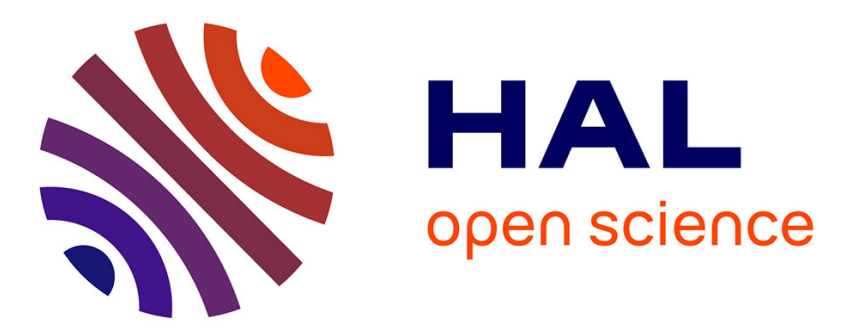

\title{
Analysis of the yield of two groups of tropical maize cultivars. Varietal characteristics, yield potentials, optimum densities
}

Pierre Siband, Joseph Wey, Robert Oliver, Philippe Letourmy, Hubert Manichon

\section{To cite this version:}

Pierre Siband, Joseph Wey, Robert Oliver, Philippe Letourmy, Hubert Manichon. Analysis of the yield of two groups of tropical maize cultivars. Varietal characteristics, yield potentials, optimum densities. Agronomie, 1999, 19 (5), pp.379-394. hal-00885938

\section{HAL Id: hal-00885938 \\ https://hal.science/hal-00885938}

Submitted on 1 Jan 1999

HAL is a multi-disciplinary open access archive for the deposit and dissemination of scientific research documents, whether they are published or not. The documents may come from teaching and research institutions in France or abroad, or from public or private research centers.
L'archive ouverte pluridisciplinaire $\mathbf{H A L}$, est destinée au dépôt et à la diffusion de documents scientifiques de niveau recherche, publiés ou non, émanant des établissements d'enseignement et de recherche français ou étrangers, des laboratoires publics ou privés. 


\title{
Original article
}

\section{Analysis of the yield of two groups of tropical maize cultivars. Varietal characteristics, yield potentials, optimum densities}

\author{
Pierre Siband ${ }^{\mathrm{a}}$, Joseph Wey ${ }^{\mathrm{b}^{*}}$, Robert Oliver $^{\mathrm{a}^{* * *}}$, Philippe Letourmy ${ }^{\mathrm{c}}$, Hubert Manichon ${ }^{\mathrm{c}}$ \\ ${ }^{a}$ Cirad-AMIS, BP 5035, 34032 Montpellier, France \\ ${ }^{\mathrm{b}} \mathrm{Cirad} / \mathrm{INERA}$, Station de Farako Ba, Bobo Dioulasso, Burkina-Faso \\ 'Cirad-CA, BP 5035, 34032 Montpellier, France
}

(Received 15 October 1997, revised 22 January 1999, accepted 9 March 1999)

\begin{abstract}
In order to analyse the results from an on-farm survey in Burkina Faso, a model for grain yield analysis was calibrated using data from the survey. Yield was broken down into four components, each representing one phase of the growth cycle. In the model, the maximum value for each component (M) is defined by the cultivar in the region of study, and from the values that the previous components have reached. These values establish the competition level for resources that a growing component undergoes. Competition begins beyond a critical value (L) of plant density (NP). An upper boundary line is defined on the base of NP for each component. A maximum grain yield $\left(\mathrm{Y}_{\mathrm{M} / \mathrm{NP}}\right)$ is evaluated for each NP value. The greatest maximum yield $\left(\mathrm{Y}_{\mathrm{GMAX}}\right)$ is considered as a varietal characteristic under the given conditions. The model was applied to two varietal groups (local and selected varieties). It indicated that selected varieties had higher $\mathrm{Y}_{\mathrm{GMAX}}$, mainly due to different competition critical limit values $(\mathrm{L})$ and not to varietal maxima $(\mathrm{M})$. For each group of varieties, the later in the cycle a component is determined, the lower the competition limit $\mathrm{Y}_{\mathrm{M} / \mathrm{NP}}$ increases with NP up to a first competition limit. Subsequently, adjustments occur between successive components, thereby stabilizing $Y_{M / N P}\left(=Y_{G M A X}\right)$ across levels of NP. Finally, when the fraction of fertile plants is limited by NP, $Y_{M / N P}$ decreases against NP. The lowest NP enabling $\mathrm{Y}_{\mathrm{GMAX}}$, while providing the greatest potential for adjusting yield components, gives the best yields. This hypothesis was verified under field conditions. The range of population densities associated with $\mathrm{Y}_{\mathrm{GMAX}}$ and greatest potential for adjustment were also the most frequently observed on farm, indicating that farmers were probably familiar with the effects of population density on yield potential. (@ Inra/Elsevier, Paris.)
\end{abstract}

maize / model / maximum yield / density

Communicated by Jean-François Ledent (Louvain-la-Neuve, Belgium)

\footnotetext{
* Present address: Cirad-TERA, BP 5035, 34032 Montpellier, France

** Correspondence and reprints

siband@cirad.fr
} 
Résumé - Analyse du rendement de deux groupes de cultivars de maïs tropical. Caractéristiques variétales, rendements potentiels, densités optimales. En vue d'analyser un travail d'enquête en milieu paysan, au Burkina Faso, un modèle de rendement en grain du maïs est calibré sur les données de l'enquête. Le rendement est décomposé en quatre composantes, représentant chacune une phase du cycle de la culture. La valeur maximale possible de chaque composante dépend du cultivar dans la région étudiée $(M)$, et des valeurs des composantes précédentes. Celles-ci déterminent le niveau de compétition rencontré par la composante en formation. La compétition apparait à partir d'une valeur limite (L) de la densité de population de plante (NP). Une courbe enveloppe supérieure est ainsi définie pour la valeur de chaque composante en fonction de NP. Elle est formée d'une droite horizontale et d'une hyperbole. Un rendement maximal possible $\mathrm{Y}_{\mathrm{M} / \mathrm{NP}}$ est évalué pour chaque NP. Le plus haut rendement maximal possible ( $\mathrm{Y}_{\mathrm{GMAX}}$ ) est une caractéristique variétale dans la région. Le modèle est appliqué à deux groupes variétaux (variétés locales et sélectionnées). Il montre que $\mathrm{Y}_{\mathrm{GMAX}}$ des variétés sélectionnées est plus élevé, dû principalement aux valeurs des densités limites de compétition (L) des différentes composantes, et non aux maxima variétaux (M). Pour chaque variété, la limite de compétition $L$ pour une composante est d'autant plus basse que la composante se forme plus tard dans le cycle. $Y_{M / N P}$ augmente avec NP, jusqu'à la limite L la plus basse. Il présente ensuite un plateau ( $\mathrm{Y}_{\mathrm{GMAX}}$ ), dû aux compensations entre composantes successives. Lorsque NP limite la fréquence de plantes fertiles, $\mathrm{Y}_{\mathrm{M} / \mathrm{NP}}$ diminue. Les plus faibles densités permettant d'atteindre $\mathrm{Y}_{\mathrm{GMAX}}$, et les meilleures capacités de compensation entre les valeurs des composantes du rendement, donnent les meilleures chances de rendement. Ceci est vérifié au champ. Les agriculteurs choisissent le plus fréquemment ces densités. (@ Inra/Elsevier, Paris.)

maïs / modèle / rendement maximal / densité

\section{List of abbreviations}

\section{Institutions}

Cimmyt Centro Internacional de Mejoramiento de Maiz Y Trigo

Cirad Centre de coopération internationale en recherche agronomique pour le développement

IITA International Institute of Tropical Agriculture

\section{Parameters}

FP frequency of fertile plants

LCG level of competition between grains

$\mathrm{L}_{\mathrm{FP}} \quad$ competition limit at which sterile plants begin to appear

$\mathrm{L}_{\mathrm{NEP}}$ competition limit for number of ears per plant

$\mathrm{L}_{\mathrm{NGFP}}$ competition limit for number of grains per fertile plant

$\mathrm{L}_{W G}$

$\mathrm{NE}$

NEP

NG

NGP competition limit for unit grain weight number of ears per unit ground area number of ears per plant number of grains per unit ground area number of grains per plant
NGFP number of grains per fertile plant

NP number of plants per unit ground area

WG unit grain weight

$\mathrm{Y} \quad$ observed grain yield per unit area

$\mathrm{Y}_{\mathrm{M} / \mathrm{NP}}$ maximum grain yield per unit area, at a given NP

$\mathrm{Y}_{\text {GMAX }}$ greatest maximum grain yield per unit area, given by yield component relations

$Y_{R A D}$ radiation-limited grain yield per unit of area, given by a radiative model

\section{Introduction}

A multi-year survey was carried out on the maize crop on small farms in the west of Burkina Faso. The analysis of these sites required the use of a diagnostic model to organise the available information.

Maize has often been subjected to modelling (e.g. $[19,24])$. The models are not always suitable for use at the field level, or transferable without local adjustments. Also, they require information about the plant material and environmental conditions which are difficult to obtain in the context of a survey. Duncan $[11,12]$ proposed a method for determining maximum yield as a function of popu- 
lation density. This model requires experimental data for each cultivar, and is more suitable for making varietal than for on-farm situation comparisons [3].

Navarro-Garza [25] and Fleury [14] used a more analytical approach based on the assumption that individual yield components observed at maturity are indicative of the growing conditions at the time were formed. This method has been used by several researchers for various annual crops [6], notably cereals, by applying to the identified components the approach developed by Shinozaki and Kira, cited by Donald [9]. These authors assumed that for defined radiation and temperature conditions and a given cultivar, competition for resources limits the maximum value that yield components can take. Competition is associated with a certain minimum plant density. The maximum value of a given yield component depends on the value per unit area of the previous component. For example, the maximum value that the mean number of grains per plant can take depends on the population density of plants. The maximum value a component can reach is estimated from the data of the sample surveyed, assuming that at some sites, the full potential of the cultivar is expressed.

The value of a component is assumed to provide information on the behaviour of the crop during the growth phase during which the yield component was established. From this point of view, the distinction of yield components is useful only insofar as they correspond to well identified growth phases. The number of plants per unit area is fixed very early, and depends largely on the farmer's decision [35]. The first ear is initiated about 10 days after the panicle is initiated. First, its number of grain rows is established, then the number of spikelets per row is determined 1 or 2 weeks before silking [29]. The number of spikelets on the ear constitutes the limit to the number of grains which it can form. According to these same authors, the rapid elongation of the ear can continue until 10 days after silk emergence. The number of grains per ear is thus determined before the beginning of their linear growth (15-18 days after flowering), depending on the function of spikelets fertilized, and more importantly, on the survival of potential grains
[31]; the greatest fraction of the unit grain weight $(90 \%)$ is formed during the linear growth phase; growth ceases at maturity [31], which is indicated by the appearance of the black layer [7]. The periods of formation of the different maize yield components are thus quite distinct and sequential.

Tollenaar $[31,32]$ emphasised the complexity of the processes at work in yield formation: competition between organs during ear formation can lead to sterility of the plants or affect the number of grains per ear around flowering time. Asynchronous flowering can be associated with failure of fertilisation, without necessarily being its cause. Adjustments occur between source and sink: on the one hand, the number of grains is determined in relation to the reserves which are formed in the stem after the emergence of the flag leaf, and which serve as a buffer during grain growth; and on the other leaf senescence can be accelerated by insufficient filling of ears. These processes can increase or reduce the sensitivity to the environment of yield components at different stages of their formation. Finally, depending on the combination of genotype $\times$ environment, the source or the sink for assimilates may be limiting [31].

The sensitivity of yield components to a stress appears to vary in the course of their formation. The number of ears [28] is more affected as flowering approaches, even though the ears are sensitive to stress at a very early stage [2]. The number of grains is the component which usually reacts most strongly and most rapidly, especially to drought stress $[4,17,26]$, throughout its period of determination. The unit grain weight is only sensitive to environmental influences after exhaustion of the stem reserves $[31,33]$. It can be stated that the number of ears per plant, the number of grains per plant and the mean grain weight are good indicators of the growth of the crop during the pre-silking, silking and grain-filling periods, respectively.

Greater plant density is commonly associated with a fall in the number of ears per plant and with a larger proportion of sterile plants, even in the absence of nutrient deficiency or drought stress [13, 18, 21]. Similarly, the number of grains per plant remaining fertile falls markedly. The unit 
grain weight can be unaffected if the plant population is thinned out after anthesis [1]. However, in a source-limited situation, a negative relationship, differing according to growing conditions, can occur, between the number of grains per unit area and the unit grain weight [30]. Thus, negative relationships between one component and those formed previously are possible under competition. We adopted this hypothesis for our diagnostic model based on yield components.

The formulation of the relationships between components and their maximum values proposed by Navarro [25] and Fleury [14] remains qualitative. The objective of this paper is to present them quantitatively, and to translate them into an analytical framework, which can be applied to determine an adequate population density, and enable an analysis of the deviations of actual yield from potential yield [35].

\section{Materials and methods}

\subsection{General conditions of the study and data collected}

This information is detailed in another publication [36]. Only information specific to this paper is described here.

The study was carried out in the maize-growing area in the west of Burkina Faso $\left(10^{\circ}-15^{\circ} \mathrm{N}\right)$. Annual rainfall is between 800 and $1000 \mathrm{~mm}$, with a maximum in August. The mean temperature is $27^{\circ} \mathrm{C}$. Solar radiation ranges from 14 to $20 \mathrm{MJ} . \mathrm{m}^{-2} \mathrm{~d}^{-1}$. Radiation and temperature, which varied little spatially, are applicable to Bobo Dioulasso; rainfall was recorded locally using a network of raingauges representing areas of about $300-400 \mathrm{~km}^{2}$. Soils are ultisols. The varieties grown locally are mostly local, open-pollinated, traditional types, and other open-pollinated varieties from international selection programmes (Cimmyt, Cirad, IITA). These cultivars are generally tall $(3-3.5 \mathrm{~m}$ for local cultivars, $2.5-3 \mathrm{~m}$ for selected cultivars). The varieties will be denominated as 'local' or 'selected' in the text. One of them, EV422SR, is the most recent released variety, and was found at 145 sites. The selected varieties are spreading rapidly, and are adopted in a similar way by all kinds of farmers. Weed control is incomplete, and herbicides are not used; levels of fertilisation are often, but not always, very low, depending on the role of maize in the farming system and the farmer's means.

The study included 456 maize fields surveyed between 1989 and 1991, years with fairly similar weather conditions, close to the last 10-year mean. Cultivation practices and specific constraints (weeds, viruses, Striga, lodging) were recorded at the field level. Variability within fields did not allow the use of mean values per field for crop condition or yield components. These were observed for each field on two $20-30-\mathrm{m}^{2}$ plots, established near the middle of the field, and 15-20 $\mathrm{m}$ apart. On each plot, the number of plants at flowering (NP) and the number of visible ears (ear length over $10 \mathrm{~cm}$ long) at maturity (NE) were counted and given by unit of area. Grain yield (Y) and grain moisture content were measured. The unit grain weight (WG) was determined from a representative sample of 1000 grains from the harvested plot, after shelling. Grain weight was adjusted to $15 \%$ moisture (Y,WG). The area-based data were expressed per hectare. The number of grains per hectare (NG) was obtained by dividing $\mathrm{Y}$ by $\mathrm{WG}$. The way the survey was organised did not allow a direct count of the number of sterile plants at harvest (plants with no ear longer than $10 \mathrm{~cm}$ ). The mean number of ears per plant (NEP) was calculated by dividing NE by NP. The relationships between parameters were studied using the means of the two plots per field.

\subsection{Elimination of heterogeneous sites and estimation of potential yield components}

Data were screened for normality (section 2.2.1) and outliers, which were eliminated (section 2.2.2). This was performed for each component, each product of successive components and yield, and for the two groups of cultivars (local and selected) separately.

\subsubsection{Intra-site tests: elimination of unreliable values}

The statistical analysis of the data required that for each character studied, the differences between the two replicates within fields should be normally distributed across the entire sample. Observations on fields where this difference was largest in absolute terms were successively eliminated until the condition of normality was satisfied. Sixteen fields were eliminated.

\subsubsection{Inter-site tests: elimination of outliers}

The statistical analysis also required that all points belong to the same group of data. To test this, a statisti- 
cal test was applied for detecting outlying values [8]. The problem is that this test is only applicable to a sample with Gaussian (normal) distribution, but the distribution of our whole sample might not be normal. However, as the upper limit of each component is approached, it may be reasonably considered that conditions tend to be suboptimal, for which the fluctuations in the value of the variable studied are the result of different factors of which none is determinant. This corresponds to the condition of normality, and the test can be used. It is applied to the ten highest values of each distribution, and repeated until no further value has to be removed. Three sites were eliminated.

\subsubsection{Calculation of radiation-limited yield}

$\left(\mathbf{Y}_{\text {RAD }}\right)$

For the sites which were retained, a check was made to ensure that the sample included observed yields near the maximum possible for the prevailing radiation and temperature conditions.

Potential yield can be estimated using a simple model [23, 34], already used for wheat [22] to interpret yield variability between plots. The dry matter formed during a given period is a function of the energy intercepted by the canopy, and of the capacity of the canopy to convert it to plant material. Yield calculated on this basis was called 'radiation-limited yield' ( $\mathrm{Y}_{\mathrm{RAD}}$ )

$$
\mathrm{Y}_{\mathrm{RAD}}=\mathrm{G} \times \mathrm{e}_{\mathrm{c}} \times \mathrm{e}_{\mathrm{i}} \times \mathrm{e}_{\mathrm{b}}
$$

where $G$ is the incident radiation during the grain-filling period, $e_{c}$ is the climatic efficiency, $e_{i}$ is the interception efficiency and $e_{h}$ is the efficiency of conversion of energy into plant material. This was applied to the period from the end of the vegetative growth until the end of grain-filling $[19,27]$, which corresponds to the period during which photosynthesis is contributing most to grain-filling. A dynamic study of ear-filling on $\mathrm{cv}$ EV8422SR at the Farako Ba station (Bobo Dioulasso) provided a database for this calculation [35].

\subsection{Model of grain yield formation}

\subsubsection{Expression of grain yield}

According to the model proposed by Fleury [14] and Navarro-Garza [25], the grain yield can be written as:

$$
\mathrm{Y}=\mathrm{NP} \times \mathrm{NGP} \times \mathrm{WG}
$$

In order to take into account the frequent occurrence of barren plants, a frequency of fertile plants, FP, can be defined. The value of FP is between 0 and 1 , and was calculated from the mean number of ears per plant:

$$
\text { If NEP }<1, \text { FP = NEP; otherwise FP = } 1
$$

The mean number of grains per fertile plant (NGFP) is calculated as follows:

$$
\mathrm{NGFP}=\mathrm{NG} /(\mathrm{NP} \times \mathrm{FP})=\mathrm{NGP} / \mathrm{FP}
$$

The grain yield is then:

$$
\mathrm{Y}=\mathrm{NP} \times \mathrm{FP} \times \mathrm{NGFP} \times \mathrm{WG}
$$

In fact, sterile and prolific plants can co-exist on the same plot, and in these cases FP would overestimate the real frequency of fertile plants. However, this type of situation is less likely when NEP falls below one. In that case, the probability of prolific plants decreases. Above that figure, the probability of sterile plants becomes very low. It is mainly when NEP is near one, i.e. when the stresses limiting the formation of ears are low, that there is a risk that FP overestimates the frequency of fertile plants. In the absence of a more suitable indicator, equation (3) was applied to estimate FP.

\subsubsection{Maximal value of a component}

At low plant density or low grain number per plant, and thus, in the absence of significant competition among plants (or grains within the plant), it is assumed that the maximal values taken by a component are characteristic of the cultivar in the region and for the climatic conditions (radiation, temperature) prevailing that year. When competition exists, the assimilates per unit area contributing to the formation of a component are shared between the elements of this component (among plants, among grains on the plant).

The level of competition among these elements depends on their population. The competition exerted between plants to establish their NEP, FP or NGFP is a function of NP. For WG, competition is exerted at two levels: between plants (indicator being always NP); and within (competition between growing grains for a share of the energy captured by this plant being dependent on NGFP). An indicator of the level of total competition between growing grains (LCG) is the product of these two terms:

$$
\mathrm{LCG}=\mathrm{NP} \times \mathrm{NGFP}=\mathrm{NG} / \mathrm{FP}
$$

LCG is the number of grains divided by the area occupied by fertile plants. FP is therefore regarded as an estimator of that part of the land area which is truly productive.

This approach involves the concept of sequential determination of yield components. Indeed the maximum value a component can take is determined by the components established previously: FP and NGPF depend on NP, WG depends on LCG. 
The search for the highest value a component can reach under given conditions (cultivar, region, year) will be described using the example of WG, for the case of selected varieties (figure $1 f$ ). WG is plotted against LCG. The maximal values are defined by the upper boundary of the cloud of points representing all fields surveyed. For low values of LCG, it is assumed that the maximal value is independent of LCG, and mostly determined by the cultivar and the radiative conditions; the relation is a horizontal line. For high values of $\mathrm{LCG}$, the maximal value is considered to be determined by the quantity of energy available for each grain, in such a way that LCG $\times$ WG is constant; the relation is a hyperbola. The straight horizontal line and the hyperbola formalise the boundary of the distribution of points. Their intersection is defined as a limit of competition between grains.

It is assumed that this model is applicable to different yield components. In such a scheme, the boundary line defines the potential values of the component considered, for a given variety under given conditions.

\subsection{Estimation of varietal characteristics}

\subsubsection{Equations for the boundary lines}

The relationships between the following pairs of variables $\mathrm{x} \times \mathrm{y}$ are examined on the available datasets:

$\mathrm{NP} \times \mathrm{NEP}$ (and NP $\times \mathrm{FP}$, deduced from equation (2))

$$
\mathrm{NP} \times \mathrm{NGFP}
$$

$$
\mathrm{LCG} \times \mathrm{WG}
$$

The boundary lines of these relations are considered to consist of a horizontal line followed by a hyperbola (as indicated above), and the corresponding equations are calculated after fitting the boundary line to the data. The horizontal line is fitted by forcing through the highest point on the $y$ ordinate, $y_{\max }$. The hyperbola is forced through the point for which the product of the co-ordinates $x y$ is maximal, $x y_{\max }$. After the elimination of outliers, these points are the best available estimates of the expected values $\mu_{y}$ and $\mu_{x y}$ of the maxima sought. The boundary line is defined from only two maximum values. It is important to evaluate the associated uncertainty. A boundary line is defined over the range of variation observed for $\mathrm{x}$, by the relation:

$$
\mathrm{y}=\min \left[\mathrm{y}_{\max }+/-\sigma_{\mathrm{y}} ;\left(\mathrm{xy}_{\max }+/-\sigma_{\mathrm{xy}}\right) / \mathrm{x}\right]
$$

$\sigma_{y}$ and $\sigma_{x y}$ are the intra-site standard errors of $y_{\max }$ and $\mathrm{xy}_{\max }$.

$$
\begin{gathered}
\sigma_{y}^{2}=1 / n \Sigma_{n}\left[\left(y_{i 1}-y_{i}\right)^{2}+\left(y_{i 2}-y_{i}\right)^{2}\right] \\
=1 / n \Sigma_{11}\left[\left(y_{i 1}-y_{i 2}\right)^{2} / 2\right]
\end{gathered}
$$

$i$ is the site index; $y_{i}$ the average of the two replication values for the site $i$.

$$
\sigma_{y}^{2}=\Sigma_{n}\left(y_{i 1}-y_{i 2}\right)^{2} / 2 n
$$

in the same way, we can write:

$$
\sigma^{2}{ }_{x y}=\Sigma_{11}\left(x_{i 1}-x y_{i 2}\right)^{2} / 2 n
$$

The equations were determined separately for the local and selected varieties.

\subsubsection{Varietal group characteristics calculated}

For each varietal group and for each yield component, a maximum corresponding to the intercept for the equation of the line (varietal maximum $\mathrm{M}=\mathrm{y}_{\max }$ ) was determined.

A competition limit $\mathrm{L}$,

$$
\mathrm{L} \approx \mathrm{xy}_{\max } / \mathrm{y}_{\max }
$$

which is the point on the abscissa corresponding to the intersection between the line and the hyperbola. $\mathrm{L}$ was calculated using the set of equations obtained for the two components of the boundary line. It was considered necessary to determine the value $\mu_{\mathrm{L}}$ and the variance $\mathrm{F}_{\mathrm{L}}$ of $L$. The variables $x y, x$ and $y$ were not obtained independently: $x$, in the case of equation (7c) was obtained from $y$ and $x y$; likewise $y$, in the case of equations (7a) and (7b) was obtained from $x$ and $x y$. Kendall et al. [20] showed that:

$$
\mu_{L}=\mu_{(x y / y)}=\mu_{x y} / \mu_{y}-\operatorname{cov}(x y, y) / \mu_{y}
$$

and its variance:

$$
\begin{gathered}
\sigma^{2}=\sigma_{(x y / y)}^{2}=\left(\mu_{x y} / \mu_{y}\right)^{2} \\
{\left[\sigma_{x y}{ }^{2} / \mu^{2}{ }_{x y}+\sigma_{y}^{2} / \mu^{2}-2 \operatorname{cov}(x y, y) / \mu_{x y} \mu_{y}\right]}
\end{gathered}
$$

$\mathrm{L}$ can be considered to be distributed normally if $n>30$, and if $\sigma_{\mathrm{xy}} / \mu_{\mathrm{xy}}$ and $\sigma_{\mathrm{y}} / \mu_{\mathrm{y}}$ are smaller than 0.1 [5].

\subsubsection{Maximum yield as a function of population density $\left(\mathrm{Y}_{\mathrm{M} / \mathrm{NP}}\right)$}

The maximum value of a component is assumed to be determined by the values for the components established previously. The value for the first component (NP) therefore sets the upper limit for the second, and so forth: NP determines NEP and NGFP; these variables determine LCG; and LCG determines WG. The product of these successive values gives the maximum yield 
$\left(\mathrm{Y}_{\mathrm{M} / \mathrm{NP}}\right)$ for each value of NP. The greatest maximum yield obtained ( $\mathrm{Y}_{\mathrm{GMAX}}$ ) across levels of NP can be regarded as an estimate of the radiation-limited yield $Y_{R A D}$ Its standard error can be estimated from the product $x y_{\max }$ for equation (7c). In fact, under optimal conditions one can assume $\mathrm{FP}=1$, and therefore from equation (6) that $\mathrm{LCG}=\mathrm{NG}$, and from equations (5) and (6) that $\mathrm{LCG} \times \mathrm{WG}$ equals the yield.

\subsubsection{Comparisons of the mean values of the characteristics calculated}

Varietal groups can be compared for greatest maximum yield ( $\left.\mathrm{Y}_{\mathrm{GMAX}}\right)$, maximum level of yield components (M), and competition limits (L, expressed as plant densities) and calculated for individual varietal group. The mean values $\left(\mu_{1}, \mu_{2}\right)$ for varietal group parameters $\left(\mathrm{M}, \mathrm{L}, \mathrm{Y}_{\mathrm{GMAX}}\right)$ are compared using the usual Student's $t$-test:

$$
\mathbf{t}=\left|\mu_{1}-\mu_{2}\right| /\left(\sigma_{1}^{2}+\sigma_{2}^{2}\right)^{-1 / 2}
$$

The test requires that the variances $\sigma_{1}^{2}$ and $\sigma_{2}^{2}$ are not different. In the present case, the degrees of freedom $v_{1}$ and $v_{2}$ are larger than 100 , and $t$ can be considered as normally distributed.

\section{Results and discussion}

\subsection{Observed yield (Y)}

\subsubsection{Yield distribution}

The observed yields fell within a very wide range of variation: from 0.3 to $7.3 \mathrm{t} \cdot \mathrm{ha}^{-1}$ for local varieties with a mode between 1 and $2 \mathrm{t} \cdot \mathrm{ha}^{-1}$, and from 0.4 to $9.5 \mathrm{t} \cdot \mathrm{ha}^{-1}$ for selected varieties, with a mode between 3 and $4 \mathrm{t} \cdot \mathrm{ha}^{-1}$. Yield maxima were thus very high, and presented an exceptional range of variation compared with other currently available datasets: they are among the best recorded in low altitude tropical Africa, judging from the mean estimates published by the national statistical services for Burkina Faso $\left(1-2 \mathrm{t} \cdot \mathrm{ha}^{-1}\right)$ or in neighbouring countries such as Bénin $\left(0.9-1.4 \mathrm{t} \cdot \mathrm{ha}^{-1}\right.$ [37]) and Togo (1.03 that ${ }^{-1}$ [15]).

\subsubsection{Radiation-limited yield $\left(\mathrm{Y}_{\mathrm{RAD}}\right)$}

From the datasets for cv EV8422SR, the period from silking to the end of grain-filling was estimated at 47 days, with a mean daily temperature of
$24{ }^{\circ} \mathrm{C}$. Mean radiation was $17 \mathrm{MJ} \cdot \mathrm{m}^{-2} \cdot \mathrm{d}^{-1}$. Taking values of 2.49 for $e_{b}$ [16], 0.48 for $e_{c}$, [34] and 1 for $e_{i}$, a value for $Y_{R A D}$ of $9.6 \mathrm{t} \cdot \mathrm{ha}^{-1}$ is obtained.

The 3-year survey shows quite similar climatic characteristics across the years [35]. The temperatures during the months with the least sunshine were also the lowest, which should prolong the period of grain-filling and have a compensatory effect. Therefore, $\mathrm{Y}_{\mathrm{RAD}}$ probably varied little among sowing dates or among years.

Finally, however inaccurate $\mathrm{Y}_{\mathrm{RAD}}$ evaluation might be, it was in the same order of magnitude as the greatest observed yields $\mathrm{Y}$ for this cultivar.

Therefore, it is reasonable to suppose that:

- the range of situations encountered includes most of those which are likely to occur in the region;

- all of the sites included in the survey were subject to comparable conditions of radiation and temperature;

- the graphical representation of the relationships between components included situations with yields close to $\mathrm{Y}_{\mathrm{RAD}}$, and enabled us to accurately position the boundary lines for the clouds of points.

We assume that this is valid for both groups of varieties.

\subsection{Yield components}

\subsubsection{Relationships among yield components}

On the scattergrams for pairs of yield components (figure 1), it is possible to locate the two parts of the boundary line, calculate their equations and find the position of the competition limits $\mathrm{L}_{\mathrm{NEP}}, \mathrm{L}_{\mathrm{NGFP}}$ and $\mathrm{L}_{\mathrm{WG}}$, and of the limit $\mathrm{L}_{\mathrm{FP}}$.

In figure $1 b$ showing the local varieties, it appears that competition among growing grains as expressed by the product NP $\times$ NGFP $(=\mathrm{LCG})$ was constant beyond 40000 plants $\cdot$ ha $^{-1}$ : according to the model, LCG cannot exceed this value if plant density increases further. A maximum also appears to exist for LCG for the selected varieties (figure $1 e$ ). According to figure $l c$ and $f$, the maxi- 
mum mean WG (within the boundary lines) varied between 260 and $390 \mathrm{mg}$ (local varieties) and between 306 and $420 \mathrm{mg}$ (selected varieties), depending on NP.

From these relationships, others can be derived that describe the relationship of competition with NP. The relationship of LCG with NP in figure $2 a$ is derived from figure $1 b$. For any given value of $\mathrm{NP}$, there is a single corresponding maximum value for LCG. On the basis of this, the relationship of the competition limit $\mathrm{L}_{\mathrm{WG}}$ with NP can be calculated. The value of $L C G$ at which $L_{W G}$ is reached is indicated in figure $1 c$; the value of NP corresponding to this value of LCG is calculated from figure $2 a$.

Thus, the limit of competition between grains $\mathrm{L}_{\mathrm{WG}}$ may be expressed not only as a function of LCG but also as a function of NP, as this applies to $\mathrm{L}_{\text {NEP }}, \mathrm{L}_{F P}$ and $\mathrm{L}_{\mathrm{NGFP}}$. The relationship of $\mathrm{WG}$ with NP may be found in the same way.

\subsubsection{Varietal characteristics (tables I and II)}

\subsubsection{Varietal maxima}

According to the calculated values of the varietal characteristics, the two groups of cultivars are not very prolific, and are not distinct according to NEP (table $)$. The traditional varieties have significant, but slightly maximum higher NGFP and slightly lower maximum WG than the selected varieties. The maximum grain weight per plant is not different for the two groups.

\subsubsection{Density limits to competition}

In interpreting the results, the extent of competition will be considered to depend on the ratio between assimilate and demand: competition increases with increasing NP or when plants are more demanding (e.g. tall varieties have a higher demand); or conversely, when the available resources per unit area are more limited (low supply).

It is observable that the low population level (27 100-35 200 plants.ha ${ }^{-1}$, depending on the varietal group) at which competition that affects WG within a stand begins to appear (table I) agrees well with tall tropical maize varieties, which may display a competition effect at lower densities than temperate ones [10]. The density limit seems higher for the establishment of the number of ears per plant $\left(\mathrm{L}_{\mathrm{NEP}}\right)$ than for the number of grains per plant $\left(\mathrm{L}_{\mathrm{NGFP}}\right.$ ) (table $\left.I I\right)$, implying a lower competitive pressure for NEP. This may be related to the growth stage at which the two components develop: NEP is determined between ear initiation and flowering, when vegetative growth is incomplete and the canopy is still closing. NGFP appears after the gaps in the canopy are closed, and at a time when the plant's demand for external resources is high. The competition limit for mean grain weight $\left(\mathrm{L}_{\mathrm{WG}}\right)$ was even lower, indicating more intense competition. This might be due to the progressive senescence of the foliage, which reduces the utilisation efficiency for the intercepted radiation. This would cause an increased competition for assimilates between grains, through supply limitation.

The selected varieties seem to tolerate significantly higher density limits to competition than the local varieties (table I): $20 \%$ higher for the first components to be established, and $30 \%$ higher for WG. This is related to a smaller individual plant size.

\subsubsection{Greatest maximum yield ( $\mathrm{Y}_{\mathrm{GMAX}}$ )}

The greatest maximum grain yield ( $\mathrm{Y}_{\mathrm{GMAX}}$, table I) may be calculated if the plant density reaches the lowest competition density limit $\left(\mathrm{L}_{\mathrm{WG}}\right)$. For the selected varieties it was about $30 \%$ higher than for local varieties. The difference was directly related to the increase in the competition density limit.

With regards to the plant type, the selection of maize cultivars in the region of study seems to have been based essentially on the size of the plants, while retaining their individual production potential. This agrees completely with data from the literature (e.g. [10]).

Examination of varietal characteristics (potential values for yield components, density limits for their expression, differences between tropical varietal groups) highlights several consistent traits: i) the values of the limits for various yield components reflect the dynamics of the system: competition sets in at lower densities as the season 
$\underline{\text { local varieties }}$

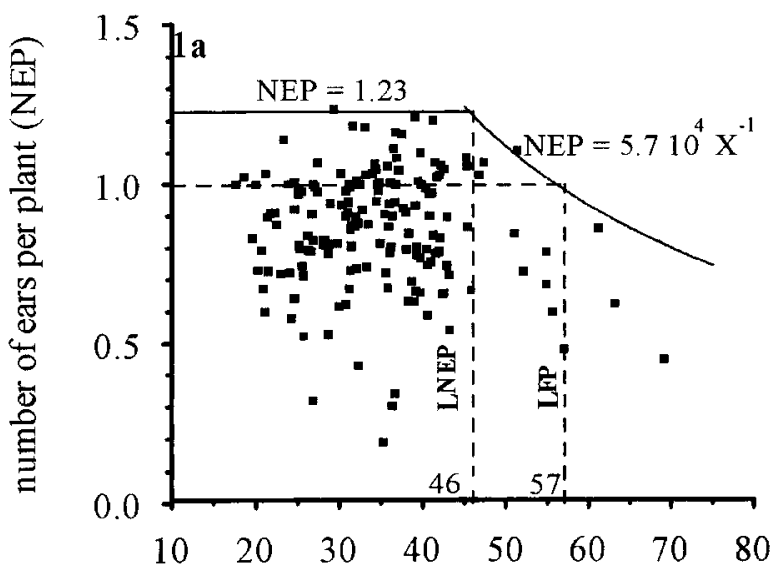

selected varieties

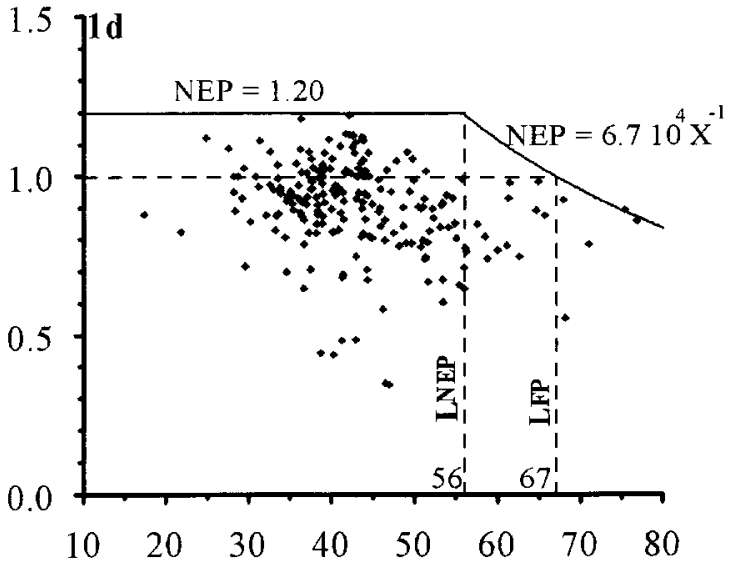

2ิ number of plants per hectare (NP $\left.10^{-3} \mathrm{ha}^{-3}\right)$

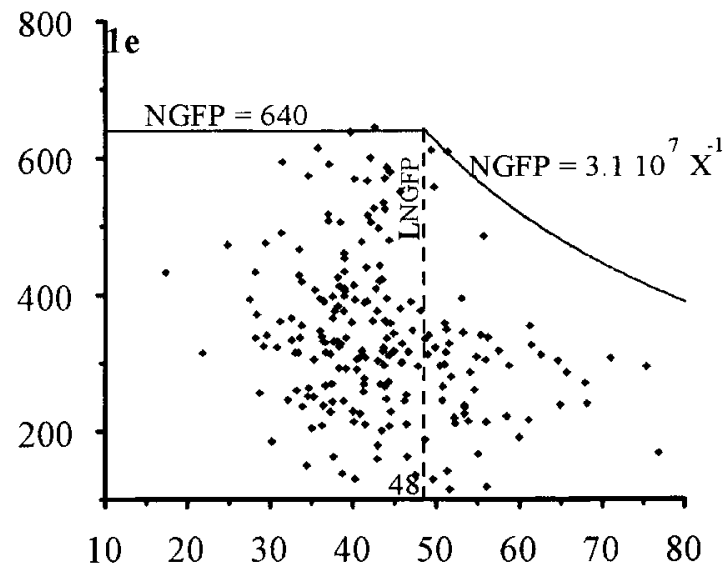
number of plants per hectare (NP $10^{-3} \mathrm{ha}^{-1}$ )
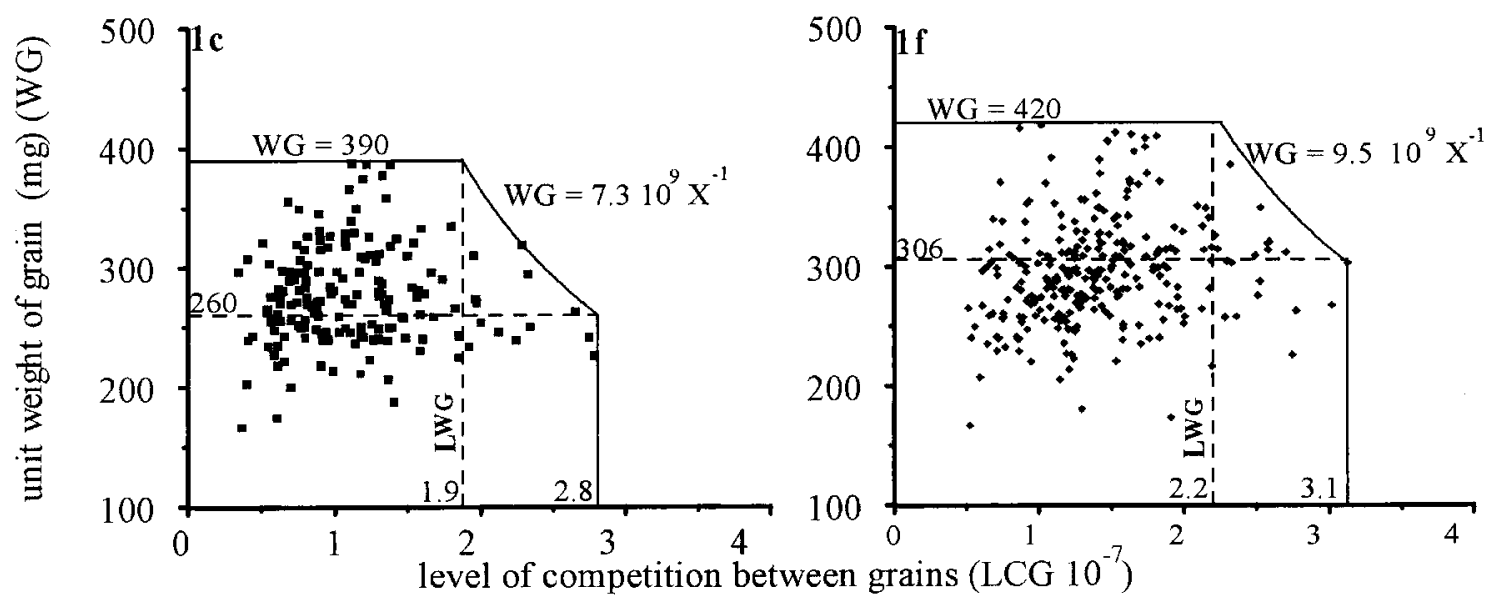

Figure 1. Boundary lines of relationships between yield components. 
Table I. Comparison of characteristics of varietal groups.

\begin{tabular}{|c|c|c|c|c|c|}
\hline \multirow[t]{2}{*}{ Varieties } & \multicolumn{2}{|c|}{ Local } & \multicolumn{2}{|c|}{ Selected } & \multirow[b]{2}{*}{$\operatorname{prob}^{2}$} \\
\hline & Mean & $s d^{1}$ & Mean & $s d^{!}$ & \\
\hline \multicolumn{6}{|l|}{ Varietal maxima } \\
\hline 1. Number of ears per plant (NEP) & 1.21 & 0.06 & 1.23 & 0.06 & 0.38 \\
\hline 2. Number of grains per plant (NGFP) & 690 & 38 & 640 & 38 & 0.14 \\
\hline 3. Unit grain weight (WG, $\mathrm{mg}$ ) & 390 & 12 & 420 & 8 & 0.01 \\
\hline 4. $2 \times 3=$ weight of grain per plant $(W G P, g)$ & 270 & 9 & 270 & 9 & 0.99 \\
\hline \multicolumn{6}{|l|}{ Density limits to competition (NP.10-3) } \\
\hline 1. $\mathrm{L}_{\mathrm{NEP}}$ & 46.3 & 3.3 & 55.8 & 3.5 & 0.02 \\
\hline 2. $\mathrm{L}_{\mathrm{FP}}$ & 56.6 & 3.3 & 67.0 & 3.5 & 0.01 \\
\hline 3. $\mathrm{L}_{\mathrm{NGFP}}$ & 40.3 & 6.3 & 48.8 & 4.7 & 0.14 \\
\hline 4. $\mathrm{L}_{\mathrm{WG}}$ & 27.1 & 1.8 & 35.2 & 2.1 & 0.01 \\
\hline Greatest maximum grain yield $\left(\mathrm{Y}_{\mathrm{GMAX}}, \mathrm{t} \cdot \mathrm{ha}^{-1}\right)$ & 7.3 & 0.4 & 9.5 & 0.5 & 0 \\
\hline
\end{tabular}

${ }^{1} \mathrm{sd}=$ standard deviation; ${ }^{2}$ prob = probability of significance level (test of difference between varieties).

Table II. Level of significance of tests of equality of competition limits (L) relative to the different components.

\begin{tabular}{lcccc}
\hline & $\mathrm{L}_{\mathrm{WG}}$ & $\mathrm{L}_{\mathrm{NGFP}}$ & $\mathrm{L}_{\mathrm{NEP}}$ & $\mathrm{L}_{\mathrm{FP}}$ \\
\hline Local & 0.02 & 0.20 & 0.02 \\
Selected & 0.01 & 0.12 & 0.01 & \\
\hline
\end{tabular}

$\mathrm{L}_{\mathrm{FP}}=$ limit at which sterile plants begin to appear; $\mathrm{L}_{\mathrm{NE} P}=$ competition limit for number of ears per plant; $\mathrm{L}_{\mathrm{NGFP}}=$ competition limit for number of grains per fertile plant; $L_{W G}=$ competition limit for unit grain weight.

advances, i.e. as the plants get larger (before flowering) or as the foliage gets older and less efficient (after flowering); ii) similarly, the classification of varieties agrees with expectation, the tallest varieties exhibiting competition at a lower population. This was true at each competition limit.

\subsection{Population density and calculated maximum yield $\left(\mathrm{Y}_{\mathrm{M} / \mathrm{NP}}\right)$}

The equations established and the parameters calculated can be used to describe the maximum grain yield as a function of population density for each varietal group. This curve is shown in figure 3 for the example of the local varieties and in figure 4 for the two groups:

- below $\mathrm{L}_{W G}$, there is no competition among plants, which can all form ears. The number of grains per plant $($ NGP $=$ NGFP $)$ and their unit weight (WG) are independent of plant density, to which yield is linearly related;

- between $\mathrm{L}_{\mathrm{WG}}$ and $\mathrm{L}_{\mathrm{NGFP}}$, the number of ears per plant (NEP) and the number of grains per fertile plant (NGFP) remain constant, such that the number of grains per square meter $(\mathrm{NG})$ and the level of competition between grains (LCG) increase with density, whereas unit grain weight $(\mathrm{WG})$ falls: $\mathrm{Y}_{\mathrm{M} / \mathrm{NP}}(=\mathrm{NG} \times \mathrm{WG})$ no longer increases;

- beyond $\mathrm{L}_{\mathrm{NGFP}}$, NGFP decreases as NP increases, thereby stabilising LCG (and consequently WG) and NG. As long as all the plants produce grain, $\mathrm{Y}$ is constant;

- beyond $\mathrm{L}_{\mathrm{NEP}}$, prolificacy declines, but without effect on $\mathrm{Y}_{\mathrm{M} / \mathrm{NP}}$ until $\mathrm{L}_{\mathrm{FP}}$. The increase in NP compensates for the decrease in NGFP.

Across these three parts of the curve (from $\mathrm{L}_{\mathrm{WG}}$ to $\left.\mathrm{L}_{\mathrm{FP}}\right), \mathrm{Y}_{\mathrm{M} / \mathrm{NP}}$ does not vary with $\mathrm{NP}$, a plateau in 

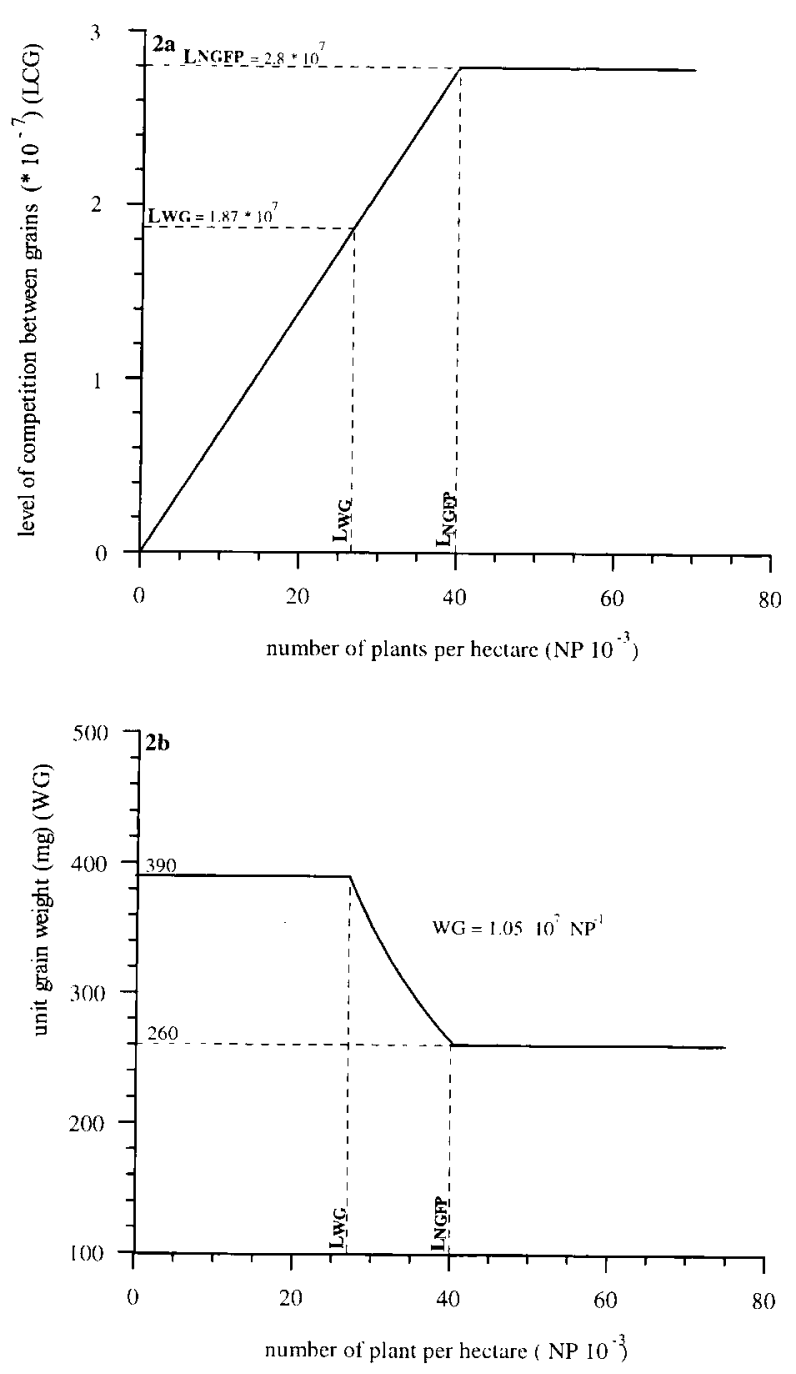

Figure 2. Expression of $\mathrm{L}_{W G}$ and $\mathrm{L}_{\mathrm{NGFP}}$, and of WG and LCG as functions of plant density. Example of local cultivars. $\mathrm{LCG}=$ level of competition between grains; $\mathrm{L}_{\mathrm{NGFP}}=$ competition limit for number of grains per fertile plant; $L_{W G}=$ competition limit for unit grain weight; $W G=$ unit grain weight.

the curve is reached. The plateau corresponds to $\mathrm{Y}_{\text {GMAX }}$, which theoretically equals $\mathrm{Y}_{\mathrm{RAD}}$ :

- if NP if larger than $\mathrm{L}_{\mathrm{FP}}$, sterile plants appear. LCG and WG remain constant. But, as FP decreases, NG (= LCG $\times$ FP) also decreases. As a result, the potential yield at a given population $\mathrm{Y}_{\mathrm{M} / \mathrm{NP}}$ decreases.
The model of $\mathrm{Y}_{\mathrm{M} / \mathrm{NP}}$ as a function of density has three components (increase, plateau and decrease). In all the relationships established, the two areabased components are associated with possible compensatory effects: NP, the variation of which causes variation in NGFP; and LCG, to which WG is related.

The proposed relationship between maximum grain yield and population density, with a $\mathrm{Y}_{\mathrm{M} / \mathrm{NP}}$ plateau between $\mathrm{L}_{\mathrm{WG}}$ and $\mathrm{L}_{\mathrm{FP}}$, is not consistent with the model proposed by Duncan [11, 12], and used by various authors $[3,32]$. The plateau is difficult to verify experimentally, as the absence of a limiting factor other than prevailing light and temperature is a necessary condition. Also, several population densities are needed covering the range between $\mathrm{L}_{\mathrm{WG}}$ and $\mathrm{L}_{\mathrm{FP}}$, in order to demonstrate that variation in density is compensated for by grain yield per plant. These limits are specific to cultivar type. To our knowledge, such situations have not been reported in the literature. However, yields per unit area are frequently constant across plant densities: this applies to two sets of data with two [13, 30], or even three densities [18]. The model developed here can explain this phenomenon.

It is true, however, that a direct consideration of the observation points does not clearly show this evolution with plant density (see, for example, figure 4), and that the trend of the calculated maximum yield is strongly dependent on the model chosen to be fitted to the data, and on the method of fitting.

\subsection{Observed plant population densities and yields}

\subsubsection{Distribution of population densities used by the farmers}

The lowest population density recorded was 16000 plants $\cdot \mathrm{ha}^{-1}$. Table III shows the distribution of sites by density, recorded separately for each varietal group: most of the densities recorded were lower than 50000 plants $\cdot$ ha $^{-1}$. Compared to local varieties, the selected varieties occurred much less frequently below 30000 plants $\cdot \mathrm{ha}^{-1}$, and much more often above 40000 plants $\cdot \mathrm{ha}^{-1}$. However, the 


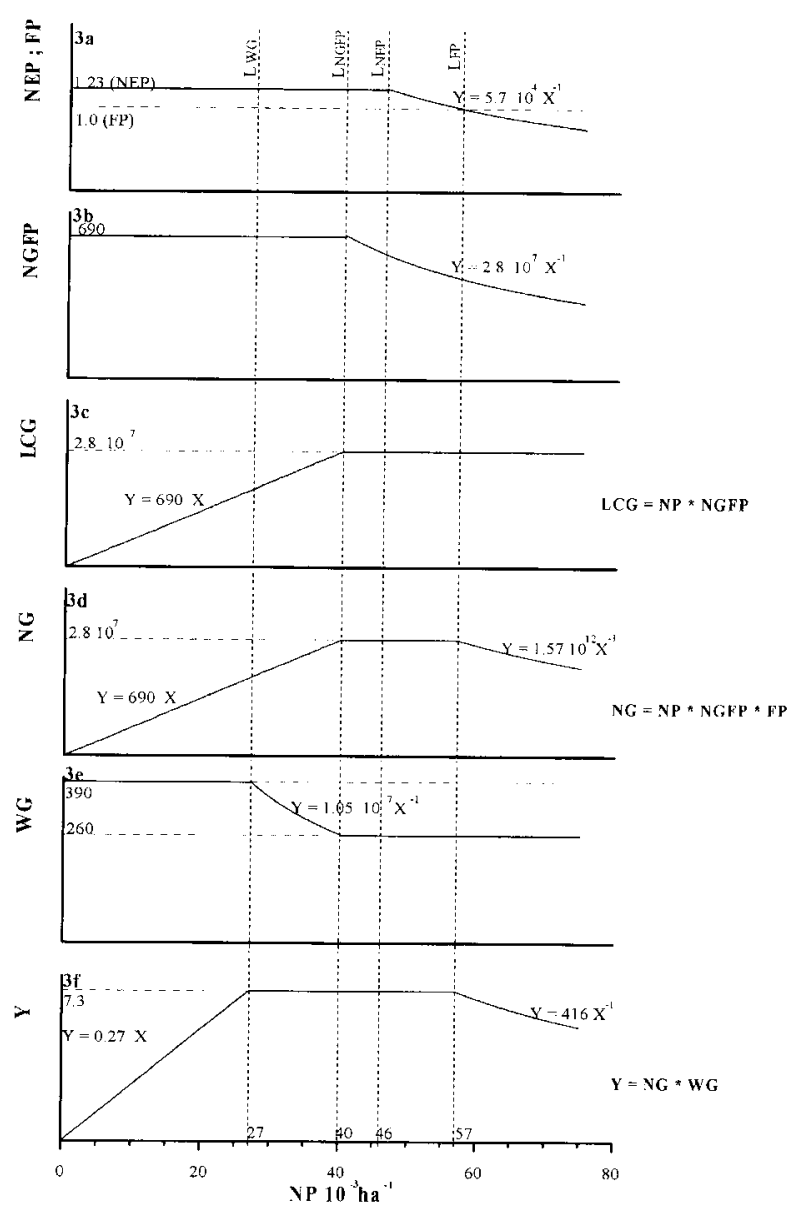

Figure 3. Behaviour of the various parameters identified in relation to plant density ( $\mathrm{X}=\mathrm{NP}$ ). Example of local cultivars. $\mathrm{FP}=$ frequency of fertile plants; $\mathrm{LCG}=$ level of competition among grains; $\mathrm{L}_{\mathrm{FP}}=$ limit at which sterile plants begin to appear; $\mathbf{L}_{\mathrm{NEP}}=$ competition limit for number of ears per plant; $\mathrm{L}_{\mathrm{NGFP}}=$ competition limit for number of grains per fertile plant; $\mathrm{L}_{W \mathrm{G}}=$ competition limit for unit grain weight; $\mathrm{NEP}=$ number of ears per plant; $\mathrm{NG}=$ number of grains per unit area of land; NGFP = number of grains per fertile plant; $\mathrm{NP}=$ number of plants per unit area of land; $\mathrm{WG}=$ unit grain weight; $\mathrm{Y}=$ grain yield
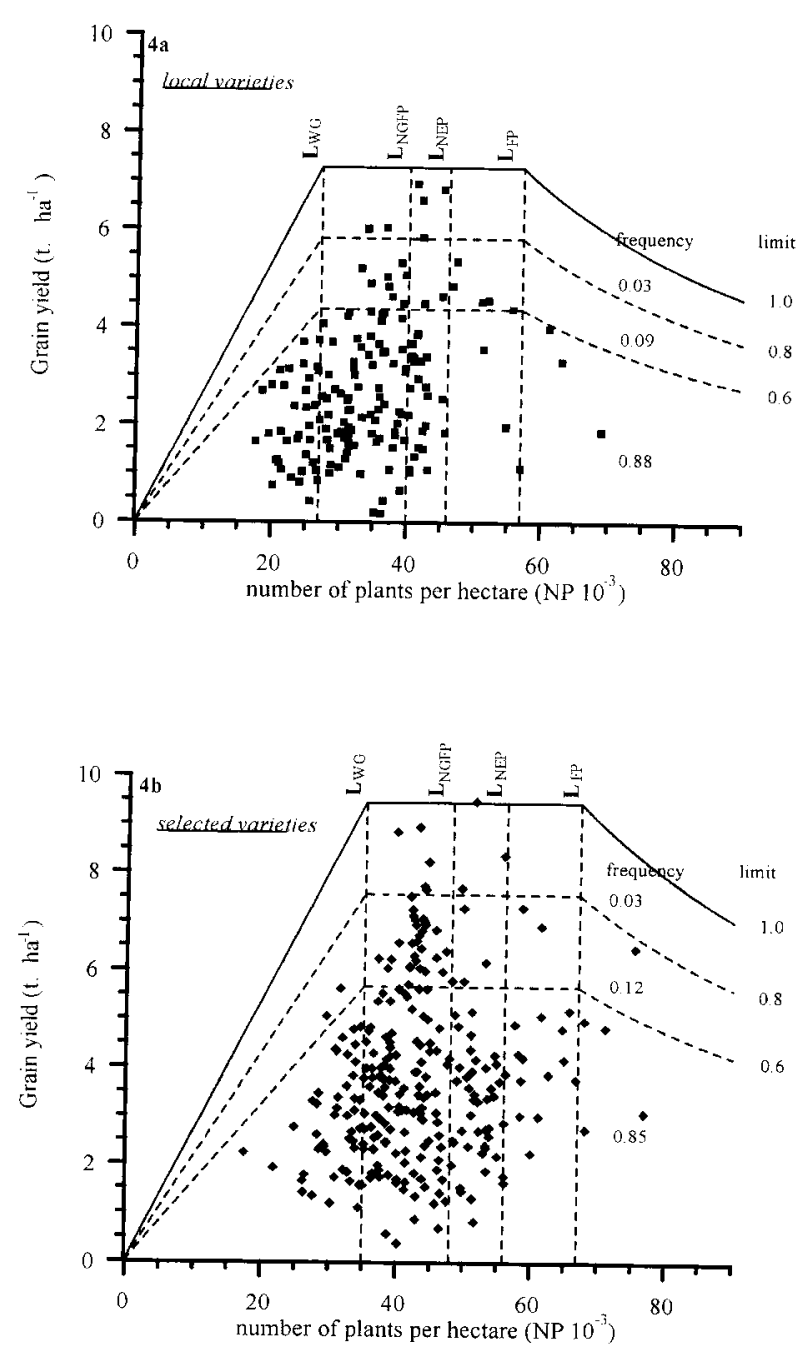

Figure 4. Measured yields and calculated maximum yields. Distribution in relation to competition limits and to percentage achievement of theoretical yield. $\mathrm{L}_{\mathrm{FP}}=$ limit at which sterile plants begin to appear; $\mathrm{L}_{\mathrm{NEP}}=$ competition limit for number of ears per plant; $\mathrm{L}_{\mathrm{NGFP}}=$ competition limit for number of grains per fertile plant; $\mathrm{L}_{\mathrm{WG}}=$ competition limit for unit grain weight.

Table III. Distribution of recorded sites according to population density.

\begin{tabular}{lccccc}
\hline $\mathrm{NP} \times 10^{3}$ (plants.ha ${ }^{-1}$ ) & $<30$ & $\geq 30 \ldots<40$ & $\geq 40 \ldots<50$ & $\geq 50 \ldots<60$ & $\geq 60$ \\
\hline Local varieties (\%) & 31 & 44 & 19 & 4 & 1 \\
Selected varieties (\%) & 6 & 33 & 40 & 17 & 5 \\
\hline
\end{tabular}

$\mathrm{P}^{2}=36.64$ (limiting value 9.49). 
Table IV. Distribution of recorded sites according to competition limits.

\begin{tabular}{lccccc}
\hline Competition limits & $<\mathrm{L}_{\mathrm{WG}}$ & $<\mathrm{L}_{\mathrm{NGFP}}$ & $<\mathrm{L}_{\mathrm{NEP}}$ & $<\mathrm{L}_{\mathrm{FP}}$ & $>\mathrm{L}_{\mathrm{FP}}$ \\
\hline Local varieties $(\mathrm{LV}, \%)$ & 22 & 53 & 17 & 6 & 2 \\
Selected varieties $(\mathrm{SV}, \%)$ & 18 & 58 & 17 & 6 & 2 \\
\hline
\end{tabular}

$\mathrm{P}^{2}=0.62$ (limit value $\left.=9.49\right)$.

$\mathrm{L}_{\mathrm{FP}}=$ limit at which sterile plants begin to appear; $\mathrm{L}_{\mathrm{NEP}}=$ competition limit for number of ears per plant; $\mathrm{L}_{\mathrm{NGFP}}=$ competition limit for number of grains per fertile plant: $\mathrm{L}_{\mathrm{WG}}=$ competition limit for unit grain weight.

Table V. Distribution of recorded sites in the low densities according to variety.

\begin{tabular}{lcc}
\hline Competition limits & $<\mathrm{L}_{\mathrm{wG}}(\mathrm{VL})$ & $<\mathrm{L}_{\mathrm{wG}}(\mathrm{VS})$ \\
\hline Local varieties $(\mathrm{LV}, \%)$ & 22 & 32 \\
Selected varieties $(\mathrm{SV}, \%)$ & 2 & 16 \\
\hline
\end{tabular}

$\mathrm{L}_{\mathrm{WG}}=$ competition limit for unit grain weight.

plant densities were mostly below those locally recommended for selected varieties $(50000$ plants.ha $\mathrm{a}^{-1}$ for low input conditions and 62500 for high input).

Grouping cases according to plant densities relative to the variety-specific competition limits (table $I V)$ virtually eliminated the differences between varietal groups. More than half of the population of each group had densities situated between $\mathrm{L}_{\mathrm{WG}}$ and $\mathrm{L}_{\mathrm{NGFP}}$. Densities greater than $\mathrm{L}_{\mathrm{NEP}}$ were rare $(8 \%)$, and cases with densities exceeding $\mathrm{L}_{\mathrm{FP}}$ were exceptional.

In summary, it appears that:

- varieties differed strongly in NP in absolute terms, but not in terms of the competition level resulting from NP. Insofar as plant densities result from farmers' decisions, rather than from variable seedling emergence, farmers seem to have a perception of varietal behaviour with respect to competition limits;

- the densities of selected varieties were mostly found between the two first competition limits $\left(\mathrm{L}_{\mathrm{WG}}\right.$ and $\mathrm{L}_{\mathrm{NGFP}}$ );

- the farmers' choices differ from the recommendations.
At a population density below $\mathrm{L}_{\mathrm{WG}}$ (table $V$ ), local varieties were virtually the only ones represented. Above this value, the selected varieties, although still less frequent than the local varieties, increased 8-fold.

\subsubsection{Distribution of observed yields (Y)}

The curves calculated for $\mathrm{Y}_{\mathrm{M} / \mathrm{NP}}$ from population density were compared with observed yield (figure 4 ). The cloud of data was subdivided into sectors according to yield reduction relative to the maximum $\left(<1.0,<0.8,<0.6\right.$ of $\left.\mathrm{Y}_{\mathrm{M} / \mathrm{NP}}\right)$ and competition limits (critical population densities).

The variability of yield within each varietal group will be analysed in a separate report [36]. In both the varietal groups, the greatest yields were observed for densities close to $\mathrm{L}_{\mathrm{NGFP}}$. These densities were slightly greater than the population range found most often (table III). At NP values above and below $\mathrm{L}_{\mathrm{NGFP}}$, observed yields were generally inferior to $\mathrm{Y}_{\mathrm{M} / \mathrm{NP}}$ : the value of $0.8 \mathrm{Y}_{\mathrm{M} / \mathrm{NP}}$ was only exceeded between $\mathrm{L}_{\mathrm{WG}}$ and $\mathrm{L}_{\mathrm{NEP}}$, and the 0.6 level, with three exceptions, was only reached between $\mathrm{L}_{\mathrm{WG}}$ and $\mathrm{L}_{\mathrm{FP}}$.

At $\mathrm{NP}>\mathrm{L}_{\mathrm{NGFP}}$, the capacity for compensation with respect to the unit grain weight is maximal (figure 3e): beyond this limit, the farmer has the best probability of achieving $\mathrm{Y}_{\mathrm{M} / \mathrm{NP}}$.

Thus, in addition to varietal considerations, other parameters were possibly associated with sowing density, and may have contributed to the farmer's choice of the low densities observed.

- An increase in sowing density is accompanied by an increase in the crop growth rate per unit area, so that interception of incident radiation is not 
complete: if it is assumed that the canopy closes at an LAI corresponding to a particular biomass, this could be reached more quickly at a higher density. The crop will act on the environment by a greater demand for resources at an earlier stage. After canopy closure, the maximum growth rate and the maximum demand for resources, which continue until flowering, will be maintained for the extra time resulting from earlier canopy closure. The increase in density thus implies an increasing demand for fertility, both in terms of the flux to be maintained and the total quantity of resources. The risk of moisture deficit is increased particularly.

- In the same way, the reduction in biomass per plant and the elongation of plants which accompany the increase in density might favour lodging. A relationship between lodging and density was not noted in this study, however, perhaps because of the superimposition of various stresses which diversify the causes of lodging, or limit its risk by limiting growth.

- In this study, sowing was carried out by hand, in hills (or planting holes) which were later thinned to two plants. Labour was proportional to the density chosen. Rapid planting of the crop is essential once the soil is sufficiently wet for good crop establishment. Hence, population density is associated with labour and risk related to the conditions of germination.

- In the same way, with high population density, yield is distributed over more and smaller ears. This increases the time required for harvesting.

Therefore, for economic reasons, NP should be close to $\mathrm{L}_{\mathrm{NGFP}}$, where the best compromise between potential yield and low risk and cost is realised.
However, one farmer out of four sowed at a higher density than $\mathrm{L}_{\mathrm{NGFP}}$. This was mainly the case for cotton farms, on which fertiliser application was frequent (table $V I$ ). This use of inputs did not affect yield, even in the best cases. In fact it is not possible to eliminate the delays in establishing the crop which are increased by the time taken for sowing, nor the increased risk of insufficient water under rainfed conditions. When the density differs considerably from $\mathrm{L}_{\mathrm{NGFP}}$, it is far too high.

Conversely, the farmer will, as a rule, only sow at a density below $\mathrm{L}_{W G}$ if he is not aiming at a high yield level, or where growing conditions are such that he cannot expect a high yield. The use of inputs is lower for both varietal groups (table VII). Under these circumstances, where there is a high risk of problems during crop growth, and where these cannot be buffered by compensation between components, yields hardly ever approach the maximum value set by the population density.

\section{Conclusion}

Maize yield was analysed as the product of four yield components which are defined successively during the course of the growth of the crop.

The maximum value that a component can take, in the absence of limiting factors other than prevailing light and temperature in the region, was assumed to be a varietal characteristic, for the region of study (assuming homogeneous conditions for temperature and light). The yield components can, however, be limited by the population densities (numbers of plants per ha or grains per ha), if these population densities are sufficiently high to cause competition within the plant stand.

Table VI. Frequency of manuring levels associated with high densities: example of selected varieties.

\begin{tabular}{lcccc}
\hline Parameters & $<\mathrm{L}_{\text {NGFP }}$ & $>\mathrm{L}_{\text {NGFP }}$ & $\chi^{2}$ & prob $^{1}$ \\
\hline High NPK dressing (125-200 kg) & 24 & 35 & 319 & 0.07 \\
High urea dressing (50-200 kg) & 21 & 31 & 290 & 0.08 \\
\hline
\end{tabular}

\footnotetext{
${ }^{\mathrm{I}}$ prob $=$ probability of a significance level; $\mathrm{L}_{\mathrm{NGFP}}=$ competition limit lor number of grains per fertile plant.
} 
Table VII. Frequency of manuring levels associated with low densities: example of local varieties.

\begin{tabular}{lcccc}
\hline Parameters & $<\mathrm{L}_{\mathrm{wG}}$ & $>\mathrm{L}_{\mathrm{wG}}$ & $\chi^{2}$ & prob $^{1}$ \\
\hline No NPK fertiliser at sowing & 44 & 21 & 808 & 0.01 \\
No supplementary urea & 53 & 32 & 551 & 0.02 \\
\hline
\end{tabular}

${ }^{1}$ prob $=$ probability of a significance level; $\mathrm{L}_{\mathrm{WG}}=$ competition limit for unit grain weight.

Because of this, the value of the first component (number of plants per hectare) frequently determines the maximum value of the following components, and finally, a maximum possible yield $\mathrm{Y}_{\mathrm{M} / \mathrm{NP}}$.

This concept allows a formal analysis of the relationships between components, and more particularly, their maximum values. Moreover, assuming normal distribution of the data, it allows assessment of the degree of uncertainty attached to them. The cultivars may thus be compared for the maximum value of the components. They may also be compared for the density limits at which competition appears, and for their calculated greatest maximum yield ( $\left.\mathrm{Y}_{\mathrm{GMAX}}\right)$, an estimation of radiationlimited yield $\left(\mathrm{Y}_{\mathrm{RAD}}\right)$.

The later the period of formation of the component in the growth cycle, the lower the population densities at which it is subjected to competition. This observation could be explained by the fact that competition increases throughout the growing period (plant size, depletion of resources in the soil, leaf senescence after flowering). Likewise, for each of the limits, competition sets in at a lower population density for the tallest cultivars. Farmers seem to be aware of the different effects of population density of the different cultivars.

The model indicates that $\mathrm{Y}_{\mathrm{GMAX}}$ can be reached over quite a wide range of plant densities owing to a capacity for compensatory growth of various yield components. Below this range, $\mathrm{Y}_{\mathrm{M} / \mathrm{NP}}$ is positively correlated with density, without the possibility of compensation. Beyond this range, some of the plants are sterile; they do not use the intercepted energy for grain production, and $\mathrm{Y}_{\mathrm{M} / \mathrm{NP}}$ decreases. This concept is difficult to verify experimentally, but agrees with some results found in the literature, and is compatible with the present results.

Within the range of densities with constant $\mathrm{Y}_{\mathrm{M} / \mathrm{NP}}$, the capacity for compensation between components increases up to the competition limit for NG, and then stabilises. On the other hand, the demand for resources grows as NP increases. Consequently, $\mathrm{L}_{\mathrm{NGFP}}$ constitutes the population density associated with the best yield under the conditions studied. This is well supported by the available dataset. In fact, the densities close to this limit were also those most frequently encountered.

This analysis only defines an upper boundary below which yields fluctuate considerably. The actual yield variability depends on various stresses, which were not studied here.

Acknowledgements: The authors wish to express their gratitude to Professor Jean François Ledent, from the Université Catholique de Louvain, and Dr Michael Dingkuhn, from Cirad, for the time they have spent criticising this paper, and for their numerous suggestions, which contributed greatly to its final form.

\section{References}

[1] Andrade F.H., Ferreiro M.A., Reproductive growth of maize, sunflower and soybean at different source levels during grain filling, Field Crops Res. 48 (1996) 155-165.

[2] Bertrand M., Tardieu F., Fleury A., Variabilité du nombre de rangs de l'épi du maïs, Agronomie 10 (1989) 957-964.

[3] Carmer S.G., Treatment designs to estimate optimum plant density for maximum corn grain yield, Agron. J. 69 (1977) 803-807.

[4] Claassen M.M., Shaw R.H., Water deficit effects on corn. II. Grain components, Agron. J. 62 (1970) $652-655$. 
[5] Cochran W.G., Sampling Techniques, 3rd ed., John Wiley \& Sons, NY, 1977.

[6] Combe L.,Picard D., Elaboration du rendement des principales cultures annuelles, Inra, Paris, 1994.

[7] Daynard T.B., Duncan W.G., The black layer and grain maturity in corn, Crop Sci. 9 (1969) 473-476.

[8] Dixon W.J., Extraneous values, in: Klute A. (Ed.), Methods of Soil Analysis, vol. I, American Society of Agronomy Inc., Madison, Wisconsin, USA, 1986, pp. 83-90.

[9] Donald C.M., Competition among crops and pastures, Adv. Agron. 15 (1963) 1-118.

[10] Dowswell C.R., Paliwal R.L., Cantrell R., Maize in the Third World, Westview Press, Oxford, UK, 1963.

[11] Duncan W.G., The relationship between corn population and yield, Agron. J. 50 (1958) 82-84.

[12] Duncan W.G., A theory to explain the relationship between corn population and grain yield, Crop Sci. 24 (1983) 1141-1145.

[13] Edmeades G.O., Daynard B., The development of plant-to-plant variability in maize at different planting densities, Can. J. Plant Sci. 59 (1979) 561-576.

[14] Fleury A., Méthodologie de l'analyse de l'élaboration du rendement, in: Picard D. (Ed.), Physiologie et production du maïs, Inra, Paris, 1990, pp. 279-290.

[15] Galiba M., La culture du mais en milieu paysan au Bénin et au Togo: l'expérience du projet Sasakawa Global 2000, in: Cirad, FSA-UNB (Eds.), Maïs prospère, Cirad, Montpellier, 1994, pp. 109-114.

[16] Gosse G., Varlet Grancher C., Bonhomme R., Chartier M., Allirand J.M., Lemaire G., Production maximale de matière sèche et rayonnement solaire par un couvert végétal, Agronomie 6 (1986) 47-56.

[17] Grant R.F., Jackson B.S., Kiniry J.R., Arkin G.F., Water deficit timing effects on yield components in maize, Agron. J. 81 (1989) 61-65.

[18] Jacobs B.C., Pearson C.J., Potential yield of maize, determined by rates of growth and development of ears, Field Crops Res. 27 (1991) 281-298.

[19] Jones C.A., Kiniry J.R., A Simulation Model of Maize Growth and Development, Texas A \& M University Press, College Station, 1986.

[20] Kendall M., Stuart A., Ord J.K., The Advanced Theory of Statistics, vol. 3, 4th ed., Charles Griffin \& Co Ltd, London, 1983.

[21] Lemcoff J.H., Loomis R.S., Nitrogen influences on yield determination in maize, Crop Sci. 26 (1986) 1017-1022.

[22] Leterme P., Manichon H., Estrade J.R., Analyse intégrée des rendements de blé tendre et de leurs causes de variation dans un réseau de parcelles d'agriculteurs du Thymerais, Agronomie 14 (1994) 341-361.
[23] Monteith J.L., Solar radiation and productivity of tropical ecosystems, J. Appl. Ecol. 9 (1972) 747-766.

[24] Muchow R.C., Sinclair T.R., Bennett J.M., Temperature and solar radiation effect on potential maize yield across locations, Agron. J. 82 (1990) 338-343.

[25] Navarro-Garza H., L'analyse des composantes du maïs. Application à l'étude de la variabilité du rendement dans une petite région, thèse, INA-PG, Paris. 1984.

[26] NeSmith D.S., Ritchie J.T., Effects of soil water-deficits during tassel emergence on development and yield component of maize (Zea mays), Field Crops Res. 28 (1992) 251-256.

[27] Plénet D., Fonctionnement des cultures de maïs sous contrainte azotée. Détermination et application d'un indice de nutrition, thèse, INPL, Nancy, 1995.

[28] Prine G.M., A critical period for ear development in maize, Crop Sci. 11 (1971) 782-786.

[29] Siemer E.G., Leng E.R., Bonnett O.T., Timing and correlation of major developmental events in maize, Zea mays L., Agron. J. 61 (1969) 14-17.

[30] Tanaka A.,Yamaguchi J., Dry matter production, yield components and grain yield of the maize plant, J. Fac. Agric. Hokkaido Univ. 57 (1972) 71-125.

[31] Tollenaar M., Sink-source relationships during reproductive development in maize. A review, Maydica 22 (1977) 49-75.

[32] Tollenaar M., Environmental influences on development of sink potential, kernel set and fill, in: Shannon J.C., Knievel D.P., Boyer, C.D. (Eds.), Regulation of Carbon and Nitrogen Reduction and Utilisation in Maize, The American Society of Plant Physiologists, 1986, pp. 21--33.

[33] Tollenaar M., Daynard B., Effect of defoliation on kernel development in maize, Can. J. Plant Sci. 58 (1978) 207-212.

[34] Varlet-Grancher C., Analyse du rendement de la conversion de l'énergie solaire par un couvert végétal, thèse, Sci. Nat., Paris Sud, Orsay, 1982.

[35] Wey J., Analyse de la variabilité du rendement du maïs (Zea mays) dans l'Ouest du Burkina-Faso, thèse, INPL, Nancy, 1998.

[36] Wey J., Oliver R., Manichon H., Siband P., Analysis of local limitations to maize yield under tropical conditions, Agronomie 18 (1998) 545-561

[37] Yallou C.G., Le maïs au Bénin: atouts et perspectives, in: Cirad, FSA-UNB (Eds.), Maïs prospère, Cirad, Montpellier, 1994, pp. 115-121. 